\title{
Comparison of the Physicochemical and Pharmacopeial Properties of Starches Obtained from Artocarpus odoratissimus Blanco, Nephelium lappaceum L., and Mangifera indica L. seeds with Corn Starch
}

\author{
Erna C. Arollado, ${ }^{1,2}$ Joriza Mae M. Pellazar, ${ }^{1}$ Richelle Ann M. Manalo, ${ }^{1}$ \\ Mae Pauline F. Siocson ${ }^{1}$ and Romeo-Luis F. Ramirez ${ }^{1}$ \\ ${ }^{1}$ Institute of Pharmaceutical Sciences, National Institutes of Health, University of the Philippines Manila \\ ${ }^{2}$ Department of Pharmacy, College of Pharmacy, University of the Philippines Manila
}

\begin{abstract}
Objective. This study was conducted to characterize and compare the physicochemical and pharmacopoeial properties of starches isolated from the seeds of Artocarpus odoratissimus Blanco (marang), Nephelium lappaceum L. (rambutan), and unripe green Mangifera indica L. (mango) with corn starch, as possible sources of pharmaceutical grade starch.

Methods. The starch from the seeds of these fruits was isolated and characterized through their physicochemical (organoleptic characteristics, percent yield, amylose-amylopectin ratio, bulk density, tapped density, compressibility index, Hausner ratio, angle of repose, solubility, swelling power, and viscosity) and pharmacopoeial properties (identification test, $\mathrm{pH}$, loss on drying, and limit of iron). Morphology of the granules was also assessed.

Results. The physicochemical properties showed that amylose content of the seed starches was significantly lower $(p=0.001)$ and amylopectin content significantly higher $(p=0.001)$ than the native high amylose corn starch. The lower values of bulk and tapped densities, and high values in compressibility index and Hausner ratio of the seed starches compared to corn starch may be due to their smaller particles. The results of the pharmacopoeial characterization showed compliance with the United States Pharmacopeia's (USP) acceptable limits, except for the $\mathrm{pH}$ of marang seeds.

Conclusion. The starches isolated from the fruit seeds have unique properties, but only rambutan seed starch has the most desirable physicochemical and pharmacopoeial properties that is comparable with corn starch. Rambutan seeds could be utilized as a source of starch for pharmaceutical applications.
\end{abstract}

Key Words: Mango, marang, rambutan, seeds, starch

\section{INTRODUCTION}

Starch is a polysaccharide mixture of amylose and amylopectin, which accounts for more than 50\% of human carbohydrate intake. ${ }^{1}$ It is mainly found, in large quantities, in staple foods, such as potatoes, wheat, corn,

Corresponding author: Erna C. Arollado, RPh, PhD Institute of Pharmaceutical Sciences Room 212 National Institutes of Health Building, University of the Philippines Manila 632 Pedro Gil Street, Manila, 1000 Philippines Telephone: +632 5772001 / +639178386327 Email: ips_nih@yahoo.com rice, and cassava. ${ }^{2}$ In the food industry, it is usually used as thickener, extender, emulsion stabilizer, and binder, while in the pharmaceutical industry, it is commonly utilized as tablet disintegrant, binder, glidant, and diluent. ${ }^{3}$ It is also manufactured for non-food applications such as in papermaking and bookbinding, as substitute for talcum body 
powder, for laundering clothes, for synthesizing bioplastics, and others. ${ }^{4}$

The wide application of starch in different industries requires the search for additional sources. Various plant parts have been explored as alternative sources of starch, including seeds. ${ }^{3,5}$ In previous study, mango (Mangifera indica L.) kernels constitute approximately 58\% starch. ${ }^{6}$ Although there are limited information on the starch content of rambutan (Nephelium lappaceum L.) seeds, its amylose content was found to be comparable with commercial potato and corn starches. ${ }^{7}$ On the other hand, there have been no published literature on the exact amount of starch in marang (Artocarpus odoratissimus Blanco) seeds. With the increased annual production of these fruit crops for food and export purposes, the volume of the generated fruit waste materials has also increased. Producing huge amount of discards with no economic value implies more spending for their disposal. When not managed efficiently, accumulated wastes may contribute as loci for disease vectors. Through upcycling, these wastes can be converted into useful materials which can reduce environmental pollution and increase economic value.

In this study, the starches from the seeds of rambutan, marang and unripe green mango were extracted, purified and evaluated for their physicochemical and pharmacopeial properties.

\section{MATERIALS AND METHODS}

\section{Materials}

Marang, rambutan and unripe green mango fruits were obtained from local wet markets in Manila. The fruits were authenticated by the Plant Division of the National Museum- Philippines. All other reagents used were of analytical grade except for practical grade high amylose corn starch (CS) (Sigma, S4180).

\section{Isolation of starch ${ }^{8}$}

Marang (MS) and rambutan (RS) seeds were cleaned with water to remove the seed coat. The unripe green mango seeds (GMS) were washed, dried for two days and the seed kernel was manually separated from the seed coat. The seeds were cut into small pieces, allowed to soak for $24 \mathrm{~h}$ in $0.1 \%$ sodium metabisulfite solution then immersed in $85^{\circ} \mathrm{C}$ $80 \%$ ethanol solution for $16 \mathrm{~h}$ to remove monosaccharides and oligosaccharides. Starch was extracted by grinding the soaked samples at minimum speed in a regular food blender to produce a smooth paste. The paste was allowed to settle and the supernatant liquid was removed. The residue was treated with $0.1 \mathrm{M} \mathrm{NaOH}$ and was left to sit for $18 \mathrm{~h}$ at room temperature. The top layer was removed and the remains were washed with $0.1 \mathrm{M} \mathrm{HCl}$ to neutralize the alkalinity and then washed several times using distilled water until the residue became light in color. The residue was filtered under vacuum filter to remove residual water, spread on a tray and dried in an oven at $60^{\circ} \mathrm{C}$. The dried powder was crushed and passed through a $200 \mathrm{~mm}$ mesh sieve. The powder was stored in a plastic container at $4^{\circ} \mathrm{C}$ until analyzed.

\section{Physicochemical characterization of starch}

\section{Percent yield}

The amount of starch yield on fresh basis from the fruit wastes was calculated using Equation 1.

$\%$ Starch yield, fresh basis $=\frac{W_{s}}{W_{m}} \times 100$

Where $W_{s}$ is the weight of extracted starch and $W_{m}$ is the weight of the fruit waste material used.

\section{Organoleptic characteristics}

Organoleptic characteristics were evaluated using the attributes of texture, odor, and color of the starches.

\section{Amylose-amylopectin ratio 9}

Defatting of the sample was conducted before the analysis by soaking in petroleum ether for $24 \mathrm{~h}$ and drying at $60^{\circ} \mathrm{C}$ for $5 \mathrm{~h}$. A $10 \mathrm{mg}$ sample was dissolved in $3 \mathrm{~mL} 1$ $\mathrm{M} \mathrm{NaOH}$ and placed in a water bath set at $60^{\circ} \mathrm{C}$ for $5 \mathrm{~min}$, followed by sonication for $25 \mathrm{~min}$. A $1 \mathrm{M} \mathrm{HCl}$ was added to make the solution neutral and the final solution was diluted to $10 \mathrm{~mL}$ with distilled water. A $0.2 \mathrm{~mL}$ of the solution was transferred to a test tube, and mixed with $0.2 \mathrm{~mL}$ distilled water and $1.6 \mathrm{~mL}$ iodine solution. The color was allowed to develop in the dark for $30 \mathrm{~min}$, and the absorbance was measured using UV-Vis spectrophotometer (Hitachi UH5300, Japan) at 466, 535 and $650 \mathrm{~nm}$ for amylopectin, and 535, 620 and $730 \mathrm{~nm}$ for amylose.

\section{Bulk and tapped density ${ }^{10}$}

The bulk density, $\mathrm{D}_{\text {bulk }}$, and tapped density, $\mathrm{D}_{\text {tap }}$, were calculated using Equations (2) and (3) based on the USP:

$D_{\text {bulk }}=\frac{W}{V_{0}}$
$D_{\text {tap }}=\frac{W}{V_{1}}$

Where $W$ is the weight of starch, and $V_{0}$ and $V_{1}$ are the volumes of the bulk and tapped starch, respectively.

\section{Compressibility index and Hausner ratio ${ }^{10}$}

Compressibility index and Hausner ratio were calculated from bulk and tapped densities using Equations (4) and (5), respectively:

Compressibility index $=\frac{D_{\text {tap }}-D_{\text {bulk }}}{D_{\text {tap }}} \times 100$

Hausner ratio $=\frac{D_{\text {tap }}}{D_{\text {bulk }}}$ 


\section{Angle of repose ${ }^{10}$}

Angle of repose was carried out using a $2 \mathrm{~cm}$ powder funnel with its tip affixed above a clean white paper. The powders were allowed to flow through the funnel until the apex of the cone touched the tip of the funnel. The angle of repose was calculated by measuring the height and base of the powder cone using Equation (6) below:

$\tan \alpha=\frac{\text { height of the cone of powder }}{0.5 \times \text { base }}$

\section{Morphology}

Morphology of the samples was obtained using a scanning electron microscope (SEM) (JEOL JSM-5310, USA) combined with an Oxford cathode-luminescence system. Images of the samples sputtered with gold coatings were obtained at $15 \mathrm{~kW}$ accelerating voltage and magnifications of 1000,3500 and 5000 times.

\section{Solubility and swelling power ${ }^{11}$}

A $100 \mathrm{mg}$ sample was placed in a glass tube and weighed. A $10 \mathrm{~mL}$ water was added and heated from 50 to $95^{\circ} \mathrm{C}$, with $5 \mathrm{~min}$ interval, in a water bath for $30 \mathrm{~min}$. It was then cooled to room temperature and centrifuged at $3200 \mathrm{rpm}$ for $10 \mathrm{~min}$. The supernatant was decanted and transferred carefully to a pre-weighed aluminum dish followed by drying at $100^{\circ} \mathrm{C}$ for $4 \mathrm{~h}$ and weighed until constant. Solubility was calculated using Equation (8). The weight of the wet residue in tube was recorded and the swelling power was also calculated based on Equation (9) below:

$$
\begin{aligned}
& \% \text { Solubility }=\frac{\text { Weight }_{\text {solid content of supernatant }}}{\text { Weight }_{\text {sample }}} \times 100 \\
& \text { Swelling power }=\frac{\text { Weight }_{\text {wet sediment in tube }}-\text { Weight }_{\text {sample in tube }}}{\text { Weight }_{\text {sample }}}
\end{aligned}
$$

\section{Viscosity}

Viscosity of the starch sample was evaluated using Brookfield digital viscometer (LVT Brookfield viscometer, USA).

\section{Pharmacopoeial characterization ${ }^{10}$}

\section{Identification}

A $2 \%$ sample solution was boiled for $1 \mathrm{~min}$. A $1 \mathrm{~mL}$ paste was transferred to a tube and added with $0.5 \mathrm{~mL}$ iodine solution. A positive result of orange-red to dark blue color, which disappeared on heating, was noted.

\section{$\mathrm{pH}$ measurements}

A $5 \mathrm{~g}$ starch sample was agitated continuously at a moderate speed with $25 \mathrm{~mL}$ of freshly boiled water for $1 \mathrm{~min}$. The solution was allowed to stand for $15 \mathrm{~min}$ and the $\mathrm{pH}$ was determined.

\section{Loss on drying (LOD)}

A $1 \mathrm{~g}$ sample was dried at $130^{\circ} \mathrm{C} \pm 2^{\circ} \mathrm{C}$ for $1.5 \mathrm{~h}$ in a weighing dish, placed in a desiccator for $30 \mathrm{~min}$ to cool and then weighed. LOD was calculated based on Equation (7) below:

\%LOD $\frac{\text { Weight }_{\text {initial (disht+sample) }}-\text { Weight }_{\text {final (dish+sample) }}}{\text { Weight }_{\text {sample }}} \times 100$

\section{Limit of iron}

A mixture of $1.5 \mathrm{~g}$ sample and $15 \mathrm{~mL} 2 \mathrm{~N} \mathrm{HCl}$ was filtered, and a $10 \mathrm{~mL}$ filtrate was transferred to a test tube. The filtrate was added with $2 \mathrm{~mL}$ citric acid solution (2:10) and $0.1 \mathrm{~mL}$ thioglycolic acid. A $10 \mathrm{M}$ ammonium hydroxide was added to make the solution basic to litmus paper and diluted to $20 \mathrm{~mL}$ with water. The sample solution was observed after $5 \mathrm{~min}$ and the intensity of pink color change was noted after 5 min.

\section{Statistical analysis}

The tests were done in triplicate and the data generated were reported as mean \pm standard deviation (SD). The data were analyzed by analysis of variance (ANOVA) followed by Tukey HSD post hoc test to compare the differences between the isolated starches and corn starch using Statistical Package for Social Sciences (SPSS) 23.0 software. Probabilities were considered statistically significant when $p<0.05$.

\section{RESULTS AND DISCUSSION}

The physicochemical and pharmacopoeial properties of the starch isolated from MS, RS, and GMS were compared with that of CS. The percent yield of the starch from MS, RS, and GMS were $63.78 \%, 56.06 \%$ and $29.91 \%$, respectively. The GMS yield was similar to a previous study, ${ }^{12}$ which is above $20 \%$. The samples were off-white in color, have fine texture with characteristic odor, except for GMS which was odorless.

The data for the physicochemical properties for the three samples are shown in Table 1. Amylose-amylopectin ratio determines the potential utilization of starch, but it is the amylose content that largely influence the functional properties of starch..$^{13}$ The amylose contents of MS, RS and GMS were significantly lower $(p=0.001)$ and amylopectin content significantly higher $(p=0.001)$ than the native high amylose of CS used. The amylose content of CS is close to the value of $67.8 \%$ reported from previous study. ${ }^{14}$ Variability on the sources and conditions may have influenced the amyloseamylopectin content of the isolated starch samples. ${ }^{15}$

Density measurements of starch are important for functional properties like powder flow and compactibility. ${ }^{16}$ The tapped and bulk densities of the samples were significantly lower $(p<0.05)$ than CS. The lower bulk and tapped densities exhibited by the isolated starches suggest 
Table 1. PhysicochemicaL properties of the starch samples \pm standard deviations

\begin{tabular}{lllll}
\multicolumn{1}{c}{ Property } & \multicolumn{1}{c}{ MS } & \multicolumn{2}{c}{ Isolated Starch Samples } \\
RS & \multicolumn{1}{c}{ GMS } & CS \\
Amylose & $10.06 \pm 0.86^{*}$ & $11.14 \pm 1.79^{*}$ & $18.91 \pm 3.44^{*}$ & $65.37 \pm 4.49$ \\
Amylopectin & $77.76 \pm 7.78^{*}$ & $87.73 \pm 5.93^{*}$ & $78.51 \pm 9.21^{*}$ & $30.16 \pm 4.04$ \\
Bulk density $\left(\mathrm{g} \mathrm{cm}^{-3}\right)$ & $0.34 \pm 0.01^{*}$ & $0.32 \pm 0.01^{*}$ & $0.31 \pm 0.01^{*}$ & $0.47 \pm 0.02$ \\
Tapped density $\left(\mathrm{g} \mathrm{cm}^{-3}\right)$ & $0.48 \pm 0.01^{*}$ & $0.46 \pm 0.01^{*}$ & $0.42 \pm 0.01^{*}$ & $0.61 \pm 0.01$ \\
Compressiblity Index (\%) & $27.92 \pm 0.90^{*}$ & $29.61 \pm 0.57^{*}$ & $30.64 \pm 0.77^{*}$ & $22.93 \pm 1.95$ \\
Hausner ratio & $1.39 \pm 0.02^{*}$ & $1.42 \pm 0.01^{*}$ & $1.44 \pm 0.02^{*}$ & $1.30 \pm 0.03$ \\
Angle of repose ( $\left.{ }^{\circ}\right)$ & $38.63 \pm 0.72$ & $43.64 \pm 0.79^{*}$ & $44.26 \pm 0.90^{*}$ & $39.06 \pm 1.20$ \\
Solubility (\%) & $5.53 \pm 0.67$ & $5.81 \pm 0.99$ & $6.80 \pm 1.04^{*}$ & $3.70 \pm 0.89$ \\
Swelling power (g/g) & $9.52 \pm 0.33^{*}$ & $6.45 \pm 0.22$ & $14.56 \pm 0.75^{*}$ & $6.59 \pm 0.43$ \\
Viscosity (cP) & $138.33 \pm 26.50^{*}$ & $34.17 \pm 3.82^{*}$ & $1040.00 \pm 43.59^{*}$ & $331.67 \pm 12.58$ \\
\hline
\end{tabular}

MS - Marang seed starch; RS - Rambutan seed starch; GMS - Unripe green mango seed starch; CS - Corn starch.

* Significant difference with control (CS) at $p<0.05$.

Table 2. Pharmacopoeial properties of the starch samples \pm standard deviations

\begin{tabular}{lllll}
\multicolumn{1}{r}{ Property } & \multicolumn{3}{c}{ Isolated Starch Samples } \\
& \multicolumn{1}{c}{ MS } & \multicolumn{1}{c}{ RS } & GMS & CS \\
Identification & Dark blue & Dark blue & Dark blue & Dark blue \\
pH & $3.53 \pm 0.01^{*}$ & $4.25 \pm 0.00^{*}$ & $4.23 \pm 0.01^{*}$ & $6.31 \pm 0.02$ \\
Loss on Drying (\%) & $7.11 \pm 0.27$ & $5.00 \pm 0.14^{*}$ & $4.35 \pm 0.19^{*}$ & $8.59 \pm 1.25$ \\
Limit of Iron (ppm) & $<10$ & $<10$ & $<10$ & $<10$ \\
\hline
\end{tabular}

MS - Marang seed starch; RS - Rambutan seed starch; GMS - Unripe green mango seed starch; CS - Corn starch.

${ }^{*}$ Significant difference with control (CS) at $p<0.05$.

that they are not as porous as corn starch because void spaces formed by larger powder particles are not permeated by smaller particles, which leads to less compression. ${ }^{17}$

Some of the fundamental methods for testing powder flow are compressibility index, Hausner ratio and angle of repose. ${ }^{10}$ The compressibility index describes the flow properties of powder as excellent $(<10 \%)$, fair $(16-20 \%)$, passable (21-25\%) and poor (26-31\%). Powder flowability is inversely proportional to its compressibility index. ${ }^{18}$ Similarly, Hausner ratio ranging from 1.26 to 1.34 is passable while a range of 1.35-1.45 indicates poor flow properties. The compressibility index and Hausner ratio of all the isolated starches were significantly higher than CS ( $p=0.001)$, and showed poor flow properties based on these tests. The angle of repose describes the flowability of starch powders relying on the resistance of interparticulate mobility within particles. ${ }^{19}$ The angle of repose is passable on the range of $41-45^{\circ}$ and fair when it is $36-40^{\circ}$. MS was comparable ( $p=0.939)$ with CS while GMS and RS were significantly higher than CS $(p=0.001)$. However, all the isolated starches displayed passable flow properties. This latter test is not fairly consistent with the results from compressibility index and Hausner ratio because of the non-numerical measurement of scales and the technique is different from the others. ${ }^{20}$

The low values of bulk and tapped densities and high values in compressibility index and Hausner ratio of the isolated starches may suggest poor flow properties. ${ }^{21}$ This may be due to their particle size and shape. Starch in plants have characteristic sizes, shapes, and morphology. Scanning electron microscopy indicates the size distribution of a potential excipient, which affect formulation properties such as drug release and flowability. ${ }^{22}$ The morphological structure of MS, RS, GMS and CS is shown on Figure I. CS granules are polygonal and smooth, consistent with previous literature. ${ }^{23}$ The SEM images of the isolated starch samples were irregular in shape and with smaller particle size which could be responsible for their poor flowability. ${ }^{24}$

The solubility of starch is dependent on the relative composition of amylose and amylopectin, ${ }^{25}$ while the swelling power is influenced by the hydrogen bonding of starch with water when they are heated. ${ }^{26,27}$ MS $(p=0.140)$ and RS ( $p=0.083)$ displayed comparable solubility with CS while GMS ( $p=0.001)$ displayed significantly higher solubility. For swelling power, MS and GMS were significantly higher ( $p=0.001)$ except for RS $(p=0.984)$ which was comparable with CS. GMS displayed significantly higher final viscosity than CS ( $p=0.001)$ while both MS and RS demonstrated significantly lower $(p=0.001)$ final viscosity. This may be due to high level of phosphorus in mango seed kernels which could be present as monoester phosphate. ${ }^{28}$ This phosphate group is responsible for the paste viscosity and is connected with the amylopectin portion of starch. This influences also its solubility and swelling properties. ${ }^{13}$ The low viscosities of RS and MS may be due to the interaction of fats and proteins with starch. ${ }^{29} \mathrm{RS}$ have been reported to have higher fat content of up to $38.9 \%{ }^{30}$ than $6.2 \%$ of CS. ${ }^{31}$

The results of the pharmacopoeial characterization are indicated in Table 2. All samples passed the USP criteria of dark blue color in identification test. The $\mathrm{pH}$ of $\mathrm{RS}$, GMS and CS, ranging from 4.23 to 6.31, were within the acceptable limits of 4.0 to 7.0 in the USP. However, MS 

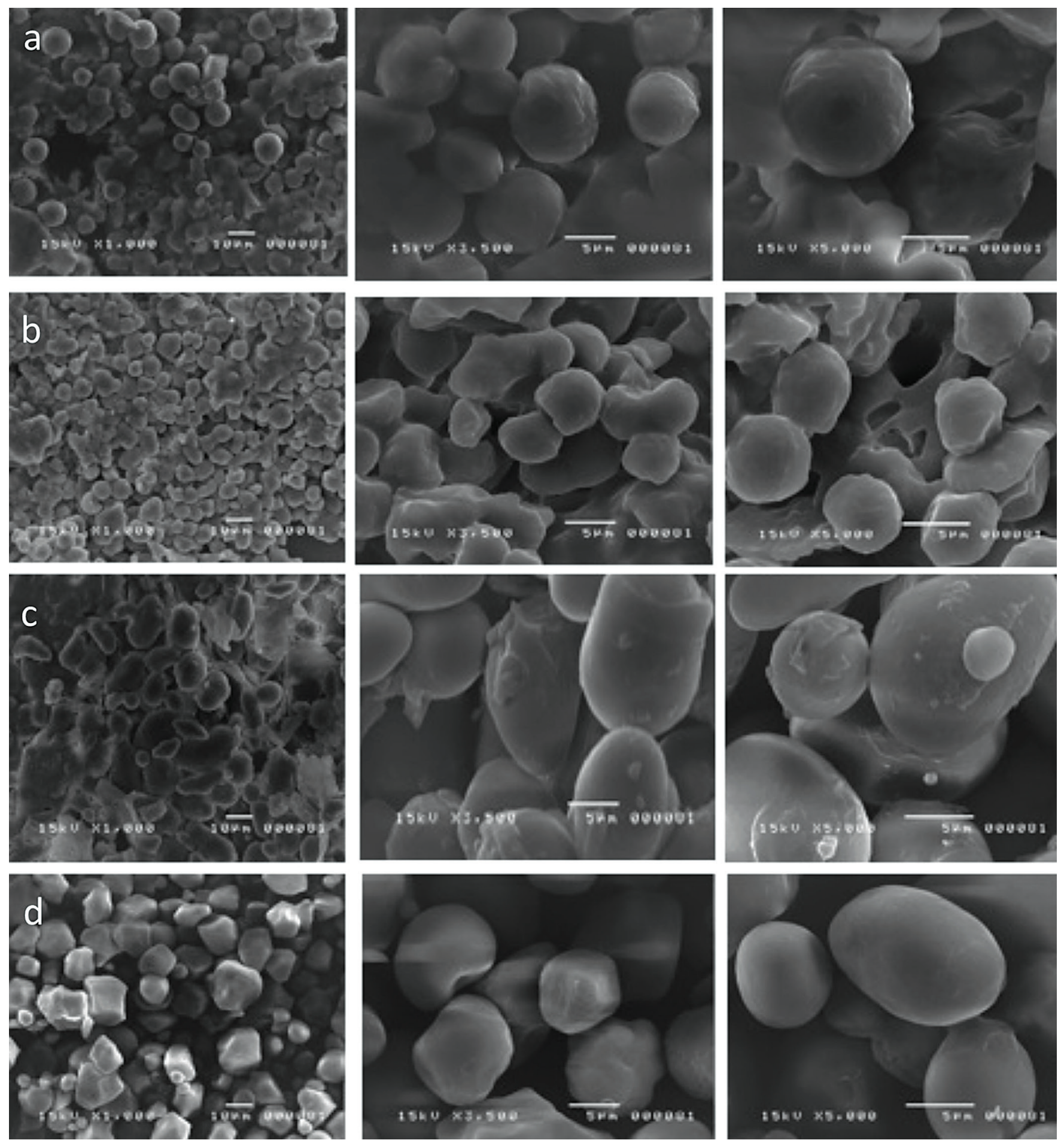

Figure 1. Micrographs of MS, RS, GMS and CS under the magnification of 1000, 3000 and 5000 times.

was acidic, with a $\mathrm{pH}$ of 3.53 which may be influenced by the insufficient washing with water during extraction. ${ }^{32}$ The samples were also within the limits of not more than $15 \%$ loss on drying as set by the USP. The test for limit of iron of the samples also complied with the acceptable criteria where the pink color is not more intense than the 10ppm standard iron.

\section{CONCLUSION}

The isolated starches from fruit by-products have unique properties which could be utilized as sources of starch in pharmaceutical applications. Among the starches, only rambutan seed starch was observed to have comparable and desirable physicochemical and pharmacopoeial 
property with corn starch. It is recommended to optimize the rambutan starch extraction process, particularly the neutralization of the samples. Moisture content of the powders should also be monitored and controlled to improve flowability.

\section{Acknowledgments}

The authors gratefully acknowledge the Philippine Institute of Traditional and Alternative Health Care (PITAHC) for funding the study and to Ms. Kerstin Mariae G. Ponsaran for her technical assistance.

\section{Statement of Authorship}

All authors have approved the final version submitted.

\section{Author Disclosure}

All authors have declared no conflict of interest.

\section{Funding Source}

This study was funded by the Philippine Institute of Traditional and Alternative Health Care (PITAHC).

\section{REFERENCES}

1. Smith AM. The biosynthesis of starch granules. Biomacromolecules. 2001; 2(2):335-41. DOI: 10.1021/bm000133c.

2. Eliasson AC. Starch in food: structure, function and applications. Starch. 2005; 57(3-4):173.

3. Remington JP. Remington, the science and practice of pharmacy. Easton, Pa: Mack Pub. Co. Pp; 1995. pp. 892-94.

4. Imam SH. Stuck on Starch: A new wood adhesive. Agricultural Research Magazine. 2000; 8-9.

5. Madruga MS, de Albuquerque FSM, Silva IRA, do Amaral DS, Magnani M, Neto VQ. Chemical, morphological and functional properties of Brazilian jackfruit (Artocarpus heterophyllus L.) seeds starch. Food Chem. 2014; 15(143) :440-5. doi: 10.1016/j.foodchem. 2013.08.003

6. Garg N, Tandon DK. Amylase activity of A. oryzae grown on mango kernel after certain pre-treatments and aeration. Indian Food Parker. 1997; 51:26-29.

7. The 9th International Conference on Starch Technology. Preparation, Microstructure and Physicochemical Properties of Rambutan (Nephelium lappaceum) Seed Starch [online]. 2017 [cited 2017 September]. Available from https://www.researchgate.net/publication/ 314116217.DOI: 10.13140/RG.2.2.28872.93449.

8. Rajeevkumar P, Rajeev R, Anikumar N. Studies on Curcuma angustifolia starch as a pharmaceutical excipient. Int J PharmTech Res. 2010; 2(4): 2456-60.

9. Wang JP, Li Y, Tian YQ et al. A novel triple-wavelength colorimetric method for measuring amylose and amylopectin contents. Starch, 2010; 62(10):508-516. https://doi.org/10.1002/star.200900242.

10. United States Pharmacopeia 40-National Formulary 35 (USP 40-NF 35). Maryland, USA: The United States Pharmacopeial Convention; 2017.

11. Walter WM Jr, Truong VD, Weisenborn DP, Carvajal P. Rheological and physicochemical properties of starches from moist- and dry-type sweet potatoes. J Agric Food Chem. 2000; 48(7):2937-42 .

12. El Saadany RMA, Foda YH, Saadany FM. Studies on starch extracted from mango seeds (Mangifera indica) as a new source of starch. Starch. 1980; 4:113-6.
13. Alcazar-Alay SC, Meireles MAA. Physicochemical properties, modifications and applications of starches from different botanical sources. Food Science and Technology. 2015; 35(2):215-36. http:// dx.doi.org/10.1590/1678-457X.6749.

14. Kaura M, Singha N, Singh K, Harmeet S, Gurayab S. Physicochemical, morphological, thermal and rheological properties of starches separated from kernels of some indian mango cultivars (Mangifera indica L.). Food Chemistry. 2004; 85(1):131-40. https:// doi.org/10.1016/j.foodchem.2003.06.013.

15. Przetaczek-Rożnowska I. Physicochemical properties of starches isolated from pumpkin compared with potato and corn starches. International Journal of Biological Macromolecules. 2017; 101:536-42. https://doi.org/10.1016/j.ijbiomac.2017.03.092.

16. Moreton RC. Excipient functionality. Pharm Technology. 2004; 28:98-99.

17. Neumann BS. The Flow Properties of Powders. Advances in Pharmaceutical Sciences. 1967; 2:181-221.

18. Emenike IV, Yusuf II, Timothy SY, et al. Evaluation of the physicochemical properties of native and modified starch obtained from Manihot esculentus as pharmaceutical excipient. Asian Journal of Pharmaceutical Science \& Technology. 2017; 7(1):34-39.

19. Adjei FR, Osei YA, Kuntworbe N, Kwakye KO. Evaluation of the Disintegrant Properties of Native Starches of Five New Cassava Varieties in Paracetamol Tablet Formulations. J Pharm. 2017; 2017:2326912. doi: 10.1155/2017/2326912.

20. Shah RB, Tawakkul MA, Khan MA. Comparative evaluation of flow for pharmaceutical powders and granules. AAPS PharmSciTech, 2008; 9(1):250-8

21. Akghari S, Sadeghi H, Ali Dabbagh M. Modification of flow and compressibility of corn starch using quasi-emulsion solvent diffusion method. Iran J Basic Med Sci. 2014; 17(8):553-9.

22. Hauschild K, Picker KM. Evaluation of a new coprocessed compound based on lactose and maize starch for tablet formulation. AAPS PharmSci. 2004; 6(2):27-38.

23. Molenda M, Stasiak M, Horabik J, Fornal J, Blaszczak W, Ornowski A. Microstructure and mechanical parameters of five types of starch. Pol.J. Food Nutr. Sci.. 2006; 15/56(2):161-8.

24. Odeku OA, Schmid W, Picker-Freyer KM. Material and tablet properties of pregelatinized (thermally modified) Dioscorea starches. Eur J Pharm Biopharm. 2008; 70(1):357-71. https://doi.org/10.1016/j. ejpb.2008.04.011.

25. Liu X, Wang Y, Yu L, et al. Thermal degradation and stability of starch under different processing conditions. Starch. 2013. 65(1-2):48-60. https://doi.org/10.1002/star.201200198.

26. Lee YE, Osman EM. Correlation of morphological changes of rice starch granules with rheological properties during heating in excess water. Applied Biological Chemistry. 1991; 34(4):379-85.

27. Sasaki T, Matsuki J. Effect of wheat starch structure on swelling power. Cereal Chem. 1998; 75(4):525-9. https://doi.org/10.1094/ CCHEM.1998.75.4.525.

28. Elegbede JA, Achoba II, Richard H. Nutrient composition of mango (Mangifera indica) seed kernel from Nigeria. Journal of Food Biochemistry. 1995; 19(5):391-8. https://doi. org/10.1111/j.1745-4514.1995.tb00543.x.

29. Eiamwat J, Wanlapa S, Sematong T, et al. Rambutan (Nepehlium lappaceum) seed flour prepared by fat extraction of rambutan seeds with SC-CO2. The International Conference on Herbal and Traditional Medicine. 2015;138-46.

30. Augustin MA, Chua BC. Composition of rambutan seeds. Pertanika. 1988; 11(2):211-5.

31. Sri Kantha S, Erdman JW. The winged beans as an oil and protein source: a review. J. Amer. Oil Chem. Soc. 1984; 61:515-24.

32. Azubuike CP, Silva BO, Okhamafe AO. Pharmacopoeial and physicochemical properties of $\alpha$-cellulose and microcrystalline cellulose powders derived from cornstalks. International Journal of Green Pharmacy. 2012; 6:193-8. 